\title{
Construction of Effective and Safe Glycemic Control in the Elderly by Using Continuous Glucose Monitoring
}

\author{
Koki Kakuta ${ }^{\text {a, b }}$, Hiroki Adachia, b, Hidekatsu Yanai ${ }^{\mathrm{a}, \mathrm{c}}$
}

\section{To the Editor}

Severe hypoglycemia is significantly associated with increased risks of a range of adverse clinical outcomes [1]. An increased risk for developing dementia by older patients with diabetes who have had episode of severe hypoglycemia has been suggested [2]. Further, patients with dementia and diabetes appear to be at greater risk for severe hypoglycemia [2]. However, excellent evidence on glycemic control in the elderly is lacking, and optimal treatment needs to be constructed collaboratively with patients, incorporating the likelihood of benefits and harms and patients preferences about treatment in older adults with type 2 diabetes [3].

To show the usefulness of continuous glucose monitoring (CGM) to determine safe and effective glycemic control in the elderly, we present our old patient who showed asymptomatic severe hypoglycemia during sleeping. An 83-year-old type 2 diabetic female patient (body height, $151.4 \mathrm{~cm}$; body weight, $56.7 \mathrm{~kg}$; BMI, $24.7 \mathrm{~kg} / \mathrm{m}^{2}$ ) was admitted to our hospital due to poor glycemic control. She has been treated by ingestion of alogliptin $(25 \mathrm{mg})$ before breakfast, and repaglinide $(1.0 \mathrm{mg})$ before every meal, and injection of insulin glargine U300 (10 $\mathrm{U})$ before breakfast. On admission, her plasma glucose and HbA1c level were $334 \mathrm{mg} / \mathrm{dL}$ and $8.7 \%$, respectively.

We changed insulin treatment from insulin glargine U300 $(10 \mathrm{U})$ to insulin degludec (IDeg)/insulin aspart (IAsp) (14 $\mathrm{U})$ which is a soluble conformation of two distinct insulin analogues in the ratio of 70\% ultra-long-acting IDeg and 30\% rapid-acting IAsp [4]. We stopped ingestion of repaglinide before breakfast because of the addition of IAsp before breakfast. We also switched from repaglinide (1.0 $\mathrm{mg}$ before lunch and dinner) to $\alpha$-glucosidase inhibitor ( $\alpha$-GI), voglibose $(0.3 \mathrm{mg}$ before lunch and dinner).

We present the result of CGM which showed the effect of

Manuscript submitted May 16, 2017, accepted May 30, 2017

a Department of Internal Medicine, National Center for Global Health and Medicine Kohnodai Hospital, Chiba, Japan

${ }^{\mathrm{b}}$ These authors equally contributed to this work.

${ }^{\mathrm{c}}$ Corresponding Author: Hidekatsu Yanai, Department of Internal Medicine, National Center for Global Health and Medicine Kohnodai Hospital, 1-7-1 Kohnodai, Ichikawa, Chiba 272-0034, Japan.

Email: dyanai@hospk.ncgm.go.jp

doi: https://doi.org/10.14740/jem425w switching from repaglinide to voglibose on glycemic control in Figure 1. CGM showed hypoglycemia early at morning (from 2 to 6 o'clock in the morning) (Fig. 1a, b) during the treatment using repaglinide. After the switching to voglibose, hypoglycemia early at morning was disappeared (Fig. 1c, d). In addition, maximal glucose level and amplitude of glucose excursion decreased, in spite of reduction of insulin dose (Fig. 1d).

Repaglinide is a short-acting, insulin-releasing agent, and has been suggested to lessen the risk of long-lasting hypoglycemia [5], however, which was observed in our patient. We should consider the development of severe hypoglycemia in the elderly whose drug clearance is diminished when we use glinides. Furthermore, our observation indicated that $\alpha$-GI does not induce long-lasting hypoglycemia and also ameliorates glycemic control in combination with insulin as compared with glinides.

We think that benefits and harms about treatment for diabetes depend largely on individuals, and individual differences get larger by aging. Therefore, we strongly recommend the construction of safe and effective glycemic control in the elderly by using CGM.

\section{Conflicts of Interest}

The authors declare that they have no conflicts of interest concerning this article.

\section{References}

1. Zoungas S, Patel A, Chalmers J, de Galan BE, Li Q, Billot L, Woodward M, et al. Severe hypoglycemia and risks of vascular events and death. N Engl J Med. 2010;363(15):1410-1418.

2. Meneilly GS, Tessier DM. Diabetes, Dementia and Hypoglycemia. Can J Diabetes. 2016;40(1):73-76.

3. Lipska KJ, Krumholz H, Soones T, Lee SJ. Polypharmacy in the Aging Patient: A Review of Glycemic Control in Older Adults With Type 2 Diabetes. JAMA. 2016;315(10):1034-1045.

4. Ma Z, Parkner T, Christiansen JS, Laursen T. IDegAsp: a novel soluble insulin analogs combination. Expert Opin Biol Ther. 2012;12(11):1533-1540.

5. Guay DR. Repaglinide, a novel, short-acting hypoglycemic agent for type 2 diabetes mellitus. Pharmacotherapy. 1998;18(6):1195-1204. 
A Treated by insulin degludec/aspart (14 $\mathrm{U})$ and alogliptin $(25 \mathrm{mg})$ before breakfast, and repaglinidle $(1.0 \mathrm{mg})$ before lunch and dinner, 2 days before switching

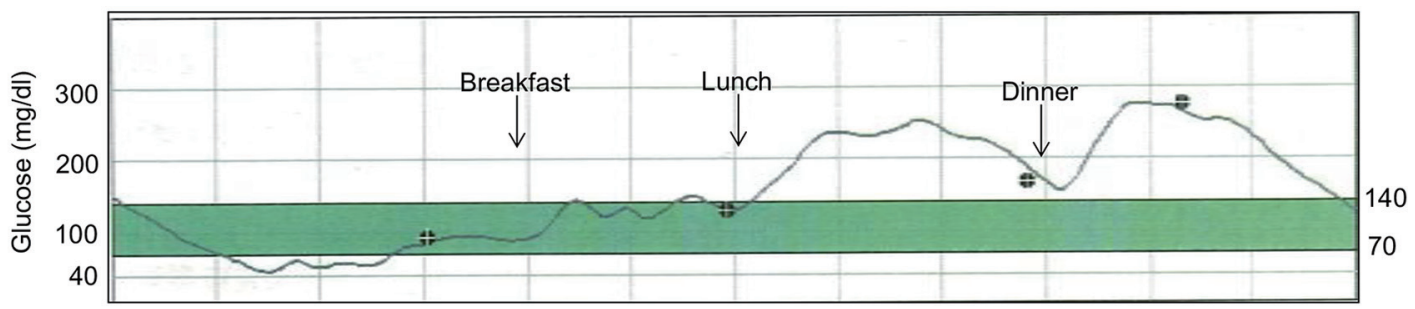

b Treated by insulin degludec/aspart (14 U) and alogliptin $(25 \mathrm{mg})$ before breakfast, and repaglinidle (1.0 mg) before lunch and dinner, the day before switching

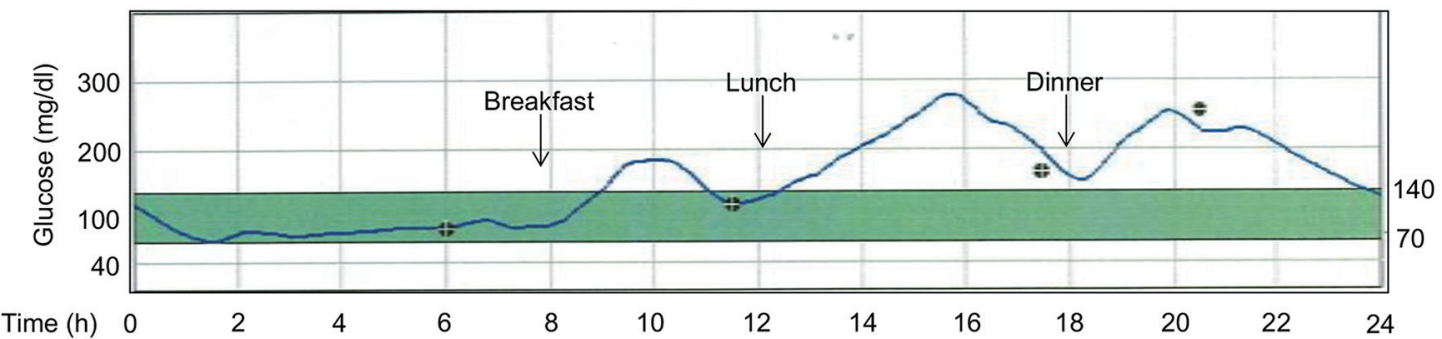

C Treated by insulin degludec/aspart $(13 \mathrm{U})$ and alogliptin $(25 \mathrm{mg})$ before breakfast, and voglibose $(0.3 \mathrm{mg})$ before lunch and dinner, the day of switching

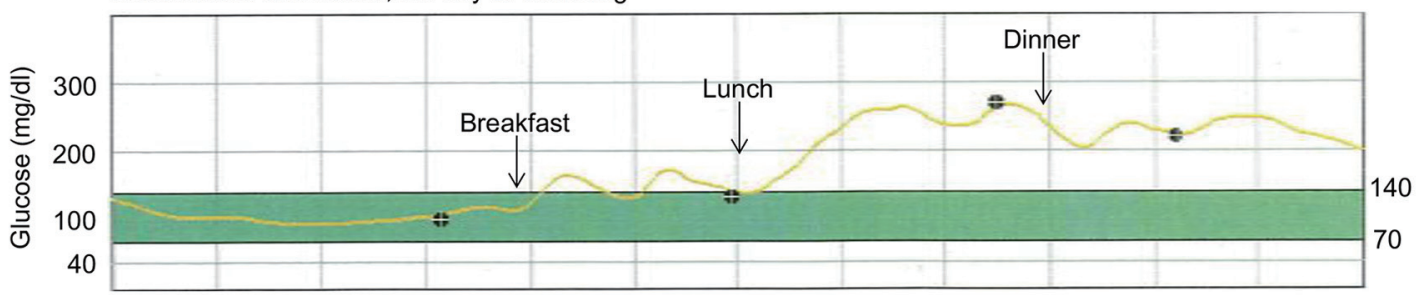

d Treated by insulin degludec/aspart (13 $\mathrm{U})$ and alogliptin $(25 \mathrm{mg})$ before breakfast, and voglibose $(0.3 \mathrm{mg})$ before lunch and dinner, the next day of switching

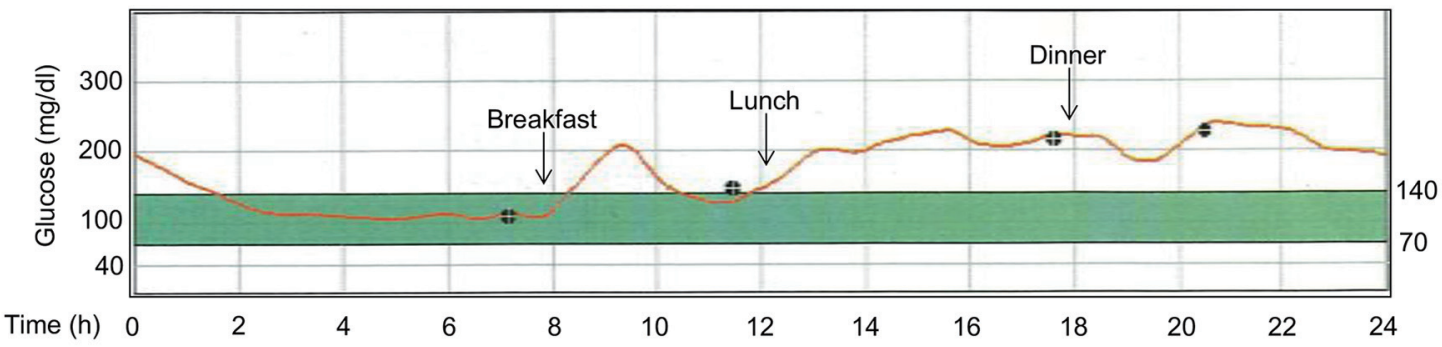

Figure 1. Continuous glucose monitoring showing the effect of switching from repaglinide to voglibose for the treatment for type 2 diabetes in old women. 